\title{
Childhood adversity and midlife suicidal ideation
}

\author{
S. A. Stansfeld ${ }^{1 *}$, C. Clark $^{1}$, M. Smuk ${ }^{1}$, C. Power ${ }^{2}$, T. Davidson ${ }^{3}$ and B. Rodgers ${ }^{4}$ \\ ${ }^{1}$ Centre for Psychiatry, Wolfson Institute of Preventive Medicine, Barts and the London School of Medicine and Dentistry, Queen Mary University of \\ London, London EC1M 6BQ, UK \\ ${ }^{2}$ Population, Policy and Practice, University College London, Institute of Child Health, 30 Guilford Street, London WC1N 1EH, UK \\ ${ }^{3}$ Centre for Gambling Research, School of Sociology, Beryl Rawson Building, The Australian National University, Acton, ACT 2601, Australia \\ ${ }^{4}$ School of Demography, The Australian National University, Acton, ACT 2601, Australia
}

Background. Childhood adversity predicts adolescent suicidal ideation but there are few studies examining whether the risk of childhood adversity extends to suicidal ideation in midlife. We hypothesized that childhood adversity predicts midlife suicidal ideation and this is partially mediated by adolescent internalizing disorders, externalizing disorders and adult exposure to life events and interpersonal difficulties.

\begin{abstract}
Method. At 45 years, 9377 women and men from the UK 1958 British Birth Cohort Study participated in a clinical survey. Childhood adversity was prospectively assessed at the ages of 7,11 and 16 years. Suicidal ideation at midlife was assessed by the depressive ideas subscale of the Revised Clinical Interview Schedule. Internalizing and externalizing disorders were measured by the Rutter scales at 16 years. Life events, periods of unemployment, partnership separations and alcohol dependence were measured through adulthood.
\end{abstract}

Results. Illness in the household, paternal absence, institutional care, parental divorce and retrospective reports of parental physical and sexual abuse predicted suicidal ideation at 45 years. Three or more childhood adversities were associated with suicidal ideation at 45 years [odds ratio (OR) 4.31, 95\% confidence interval (CI) 2.67-6.94]. Psychological distress at 16 years partially mediated the associations of physical abuse (OR 3.41, 95\% CI 2.29-5.75), sexual abuse (OR 4.99, 95\% CI 2.90-11.16) with suicidal ideation. Adult life events partially mediated the association of parental divorce (OR 6.34, 95\% CI -7.16 to 36.75) and physical (OR 9.59, 95\% CI 4.97-27.88) and sexual abuse (OR 6.59, 95\% CI 2.40-38.36) with suicidal ideation at 45 years.

Conclusions. Adversity in childhood predicts suicidal ideation in midlife, partially mediated by adolescent internalizing and externalizing disorders, adult life events and interpersonal difficulties. Understanding the pathways from adversity to suicidal ideation can inform suicide prevention and the targeting of preventive interventions.

Received 17 December 2015; Revised 22 June 2016; Accepted 26 July 2016; First published online 20 October 2016

Key words: Adversity, childhood psychological disorders, cohort studies, suicide.

\section{Introduction}

Adversity in childhood, such as parental divorce and sexual abuse, predicts increased risk of affective disorders, suicidal ideation and completed suicide in adolescence and early adulthood (Fergusson et al. 2000; Agerbo et al. 2002). Exposure to adversity can interact with genetic factors and result in altered hormonal responses to subsequent stressful life events and may have long-term consequences across the lifecourse (Bradley et al. 2008; McGowan et al. 2009; Hornung \& Heim, 2014). It is unknown whether the association of childhood adversity and suicidal ideation extends into midlife although cross-sectional studies show

\footnotetext{
* Address for correspondence: S. A. Stansfeld, Centre for Psychiatry, Wolfson Institute of Preventive Medicine, Charterhouse Square, London EC1M 6BQ, UK

(Email: s.a.stansfeld@qmul.ac.uk)
}

associations of retrospectively recalled childhood adversity and suicide in adulthood (Dube et al. 2001; Bifulco et al. 2002; Fanous et al. 2004; Corcoran et al. 2006; Enns et al. 2006; Fairweather et al. 2007; Heider et al. 2007; Afifi et al. 2008) and sexual and physical abuse in childhood (Fanous et al. 2004; Ystgaard et al. 2004). In this context, retrospective recall of childhood adversity has been found to be biased by contemporaneous adult mental ill-health (Colman et al. 2016).

Little is known of potential pathways between childhood adversity and adult suicidal ideation but pathways via adult affective disorders may be relevant. The association of childhood adversity with adult suicidal ideation may be mediated through early onset of psychopathology (Fanous et al. 2004). Early-onset psychopathology is associated with increased risk of psychopathology in adulthood (Clark et al. 2007) and repeated internalizing disorders in childhood are associated with greatly increased risk of further

This is an Open Access article, distributed under the terms of the Creative Commons Attribution licence (http://creative commons.org/licenses/by/4.0/), which permits unrestricted re-use, distribution, and reproduction in any medium, provided the original work is properly cited. 
psychopathology across the lifecourse and hence with suicidal ideation (Colman et al. 2007). Alternatively, the association of childhood adversity with adult suicidal ideation may be mediated through increased exposure to life events in adulthood (Fergusson et al. 2000), where early adversity exposure predicts adulthood adversity exposure either through trajectories of social disadvantage (Graham \& Power, 2004) or through selection of adverse environments (Kendler \& Eaves, 1986).

Kendler's developmental model for major depression in women (Kendler et al. 2002) and men (Kendler et al. 2006) includes three broad pathways: through the development of internalizing disorders, externalizing disorders, and adult interpersonal difficulties (adult adversity). This developmental model tested on twin samples has been innovative, integrating the multifactorial aetiology of adult depression, incorporating both genetic and environmental influences. The model explains a large proportion of the variance in the liability for adult depressive episodes in women (52\%) and men (49\%). The final model was very similar in women and men. In all, 18 predictor variables were organized across five tiers: childhood (genetic risk, disturbed family environment, sexual abuse, parental loss); early adolescence (neuroticism, self-esteem, anxiety and conduct disorder); late adolescence (educational attainment, lifetime traumas, social support, substance misuse); adulthood (divorce, history of major depression); and last year (marital problems, independent/dependent life events) (Kendler et al. 2002). Neuroticism and early-onset anxiety disorders were the most powerful influences in the internalizing pathway, with conduct disorder and substance misuse being most powerful in the externalizing pathway. The adult interpersonal difficulty pathway was more complex: childhood adversity influenced low educational attainment, lifetime trauma and low social support. The authors comment that 'many of the depressogenic consequences of the earlier adversities appear to be in the realm of troubled interpersonal relationships' (Kendler et al. 2002).

We examined these three pathways for the associations between childhood adversity at 7, 11 and 16 years and suicidal ideation at 45 years in participants from the British National Childhood Development Study (1958 Birth Cohort). We hypothesized that: (1) childhood adversity predicts suicidal ideation at midlife; and (2) the association of childhood adversity and suicidal ideation is partially mediated through (a) internalizing disorders in childhood, (b) externalizing disorders in childhood and (c) increased exposure to life events and interpersonal difficulties in adulthood.

\section{Method}

\section{Setting}

Data were from the 1958 British Birth Cohort, a study of $98 \%$ of births in England, Scotland and Wales during 1 week in $1958(n=17416)$. Analyses were based on 9377 participants in a clinical survey at 45 years. The response rate for the clinical survey was $78 \%$ of those invited, representing $54 \%$ of the surviving population (Power \& Elliott, 2006). Information was available from parents and schools at ages 7, 11 and 16 years and by participant interviews at ages 7, 11, 16, 23, 33 and 42 years. Ethical approval for the survey was given by the South East Multi-Centre Research Ethics Committee: informed consent was obtained. The authors assert that all procedures contributing to this work comply with the ethical standards of the relevant national and international committees on human experimentation and with the Helsinki Declaration of 1975, as revised in 2008.

\section{Measures}

\section{Midlife suicidal ideation}

Two measures captured suicidal ideation in midlife: depressive ideas and a single-item measure on whether life is worth living. Depressive ideas were assessed using the Revised Clinical Interview Schedule (CIS-R) (Lewis et al. 1992), administered by a trained research nurse using computer-assisted personal interviewing in the home-based clinical examination at 45 years. The CIS-R measures International Classification of Diseases, tenth edition (ICD-10) affective and anxiety diagnoses in the past week. Two measures of suicidal ideation were derived from CIS-R data. A 'depressive ideas' scale in the past 7 days was formed by summing affirmative answers to the following questions: 'Have you on at least one occasion felt guilty or blamed yourself when it hasn't been your fault?'; 'During the past week have you been feeling you are not as good as other people?'; 'During the past week have you felt hopeless about your future?'; 'In the past week have you felt that life isn't worth living?'; In the past week have you thought of killing yourself?'. This five-point scale is dichotomized at $\geqslant 2$ to indicate a clinically significant level of depressive ideas based on CIS-R scoring protocols (Lewis et al. 1992). A single item from this scale was also examined as an outcome: 'In the past week have you felt that life is not worth living?' - analysed as a dichotomous outcome.

\section{Childhood adversity}

Childhood adversity was defined as exposure to traumatic events or chronic stressors (Tiet et al. 1998). 
Prospectively assessed measures of childhood adversity were available from data collected at 7, 11 and 16 years from the cohort member, their parent (usually the mother), the interviewer, the school/teacher and medical examination. These items are detailed elsewhere (Clark et al. 2010), but in brief:

Illness relates to any mental or physical illness within the child's household at 7, 11 or 16 years;

Neglected appearance: medical report of the child having an underfed/neglected appearance at 7 and/ or 11 years;

Maternal absence: any report of the child not living with their natural mother at 7, 11 and/or 16 years, through death, divorce, separation, illegitimacy or being in institutional care;

Paternal absence similarly reported the father's absence;

In care: the child having been in care at 7, 11 and/or 16 years;

Parental divorce: at 33 years participants reported parental divorce by 16 years;

Physical abuse by a parent ('I was physically abused by a parent - punched, kicked, hit, or beaten with an object or needed medical treatment');

Sexual abuse by a parent ('I was sexually abused by a parent').

Physical abuse and sexual abuse were ascertained from retrospective report at 45 years (Rosenman \& Rodgers, 2004) as these data were not collected prospectively. These types of adversity are difficult to assess prospectively because children often do not report abuse at the time because of shame and adult coercion. A measure of cumulative adversity counted the reports of neglected appearance, in care, parental divorce, parental physical abuse, parental sexual abuse, and maternal and paternal absence (0, 1, 2, 3 or more): the latter two adversities were only included if parental divorce and being in care were not reported (see Clark et al. 2010). This cumulative measure attempts to account for exposure to multiple adversities across childhood.

\section{Childhood internalizing and externalizing disorders}

Internalizing and externalizing problems at 16 years were measured using the teacher version of the Rutter scales (Rutter, 1967; Elander \& Rutter, 1996). Two scales were formed by summing and square root transforming the items 'worries', 'solitary', 'miserable', 'fearful' and 'fussy' for internalizing problems and 'destructive', 'fights', 'not much liked by other children', irritable', 'disobedient', 'lies', 'steals', 'resentful/aggressive' and 'bullies' for externalizing problems. A score in the top $13 \%$ was defined as internalizing and externalizing disorders, the lowest $50 \%$ were not a case, and the remainder were borderline based on earlier studies (Ghodsian, 1983; Clark et al. 2007). These scales have demonstrated reliability in this cohort (Cronbach's $\alpha$ for internalizing problems scale $=$ 0.66, $n=7225$; Cronbach's $\alpha$ for externalizing problems scale $=0.88, n=7179)$ (Clark et al. 2007).

\section{Adult stressors and interpersonal difficulties}

Recent life events

At 45 years 13 questions from the Australian Personality and Total Health (PATH) Study (Windsor et al. 2008) measured serious illnesses and death within the family, relationship problems, work problems, unemployment, financial problems and legal/police problems. Responses were 'yes' or 'no'. A sum of the number of life events in the past 6 months was coded as 0 or $\geqslant 1$. More detailed classification of life events in the last 6 months was not possible because of the small numbers of events. Social support was assessed by a question at 42 years where participants indicated whether they had someone they could turn to for advice/support (yes/no).

\section{Lifecourse unemployment}

A count of times the participant had been unemployed (having no employment as opposed to undertaking other non-working activities such as homemaking) from 16 to 42 years was calculated from the activity histories available from 1974 to 2009 (Hancock et al. 2011a). This variable was coded as $0,1,2$ or 3 or more periods of unemployment.

\section{Lifecourse partnerships}

A count of the number of separations from a cohabiting partnership from 16 to 42 years was derived from the partnership histories for the period 1974-2008 available for the cohort (Hancock et al. 2011b). This variable was coded as 0 or 1 v. 2 or more separations.

\section{Problem drinking}

Problem drinking was included as an indicator of adult externalizing behaviours. A dichotomous variable was derived indicating problem drinking in the past year at 33 or 42 years as indicated by affirmative responses to two or more of the CAGE items (Cutting down, Annoyance by criticism, Guilty feeling, and Eye-openers) (Mayfield et al. 1974): 'They felt they should cut down'; 'People annoyed them by criticizing their drinking'; 'They felt bad or guilty about their drinking'; and 'They drank in the morning to get rid of a hangover'. 
Long-standing illness

At 42 years participants indicated if they had 'any longstanding illness, disability or infirmity', coded as yes $v$. no.

\section{Socio-economic position and educational qualifications}

Adult social position was based on current/most recent occupation at 42 years and categorized using the British Registrar General classification (Office of Population Censuses and Surveys, 1980) as: 'I and II', professional/managerial/technical; 'IIINM', other non-manual; 'IIIM', skilled manual; and 'IV and V', unskilled manual. The same measure was available for the participant's father at birth: children with an absent father at birth were coded as 'IV and V'. This classification was also available for the participant's father at birth (Stansfeld et al. 2008). Qualifications were reported at 33 years, categorized as none, 'O' levels, and 'A' levels or higher.

\section{Statistical analysis}

Analyses were carried out using STATA (version 13; StataCorp LP, USA).

\section{Imputation}

Multiple imputation, under the 'missing at random' assumption, was used to address the issue of missing data, using the ICE program in STATA. The measures described above were included in the imputation equations. Employment status at 45 years, and social class at 7 and 42 years were also included as they were significantly associated with attrition (Atherton et al. 2008). Missing data on the variables ranged from 0 to $20 \%$, except for externalizing disorders at 16 years $(22.9 \%)$, illness in the family $(26.2 \%)$, in care $(38.9 \%)$ and neglect (56.1\%) (Table 1). All participants except 1245 who had died by 45 years were included in the imputation, but analyses in this paper are restricted to participants in the 45 -year study $(n=9377)$. A total of 30 datasets of the imputation were run and analyses indicated that the measures were stable across the imputations. Parameter estimates from the 30 imputations were estimated using the MIM function in STATA. Imputed analyses are presented with unimputed prevalence figures.

\section{Modelling}

Initial logistic regression analyses, adjusting for gender, qualifications at 33 years and social position at 42 years, examined the strength of the associations between each childhood adversity measure and suicidal ideation at 45 years.
A series of logistic regression analyses were then run to test the hypothesized pathways between each of the childhood adversity measures and suicidal ideation. First, to establish whether the associations of the childhood adversity with suicidal ideation were partially mediated through internalizing and externalizing disorders, we conducted logistic regression analyses of the associations of the childhood adversities on internalizing and externalizing disorders at 16 years adjusted for gender and social class at birth. We conducted logistic regression analyses to establish whether the association of childhood adversity with suicidal ideation is through increased exposure to life events. In order to do this we examined the associations of each childhood adversity measure with recent life events at 45 years, adjusting for gender, qualifications at 33 years, and social position at 42 years.

Further logistic regression analyses assessed the associations of: (i) interpersonal difficulties (the number of partnerships, number of periods unemployed, lack of emotional support at 42 years, long-standing illness at 42 years); and (ii) adult drinking problems (at 33 or 42 years) with midlife suicidal ideation, adjusting for gender, social class at 42 years and qualifications at 33 years. Finally, the associations between childhood adversities and suicidal ideation were re-run, additionally adjusting for (a) internalizing and externalizing disorders at 16 years and $(b)$ the adulthood life events and interpersonal difficulties.

Estimated causal mediation of the associations between each childhood adversity measure and midlife suicidal ideation by: (i) internalizing disorders; (ii) externalizing disorders; or (iii) interpersonal difficulties and problem drinking was investigated using the medeff package (Hicks \& Tingley, 2011). We applied 200 bootstrapping replications, to each imputed dataset separately using 2000 simulations in each to approximate the quasi-Bayesian uncertainty parameter estimate; causal mediation estimates were then combined using Rubin's rules (Rubin, 1987). At present mediation can only be examined easily for binary and continuous variables, so mediation analyses are not presented for the multinomial cumulative childhood adversity measure.

All analyses tested for interactions between childhood adversity and gender: analyses were stratified by gender if the interaction was significant $(p<0.05)$ and adjusted for gender where not significant $(p \geqslant 0.05)$.

\section{Results}

\section{Descriptives}

Table 1 shows the unimputed frequencies for the key variables. At 45 years, $2.0 \%$ had felt that life was not 
Table 1. Unimputed frequencies and percentages for the key variables in the analyses

\begin{tabular}{|c|c|c|c|}
\hline Variable & $\begin{array}{l}\text { No. with characteristic for } \\
\text { biomedical sample at } 45 \text { years } \\
(n=9377)\end{array}$ & $\begin{array}{l}\text { Percentage with characteristic for } \\
\text { biomedical sample at } 45 \text { years } \\
(n=9377)^{\mathrm{a}}\end{array}$ & $\begin{array}{l}\text { Percentage with } \\
\text { missing data out of } \\
n=9377\end{array}$ \\
\hline Depressive ideas scale $\geqslant 2$ & 675 & 7.2 & 0.9 \\
\hline $\begin{array}{l}\text { Thought that life isn't worth living } \\
\text { in the past week }\end{array}$ & 189 & 2.0 & 0.9 \\
\hline Illness in the household (7-16 years) & 1415 & 15.1 & 26.2 \\
\hline $\begin{array}{l}\text { Neglected/underfed appearance (7- } \\
11 \text { years) }\end{array}$ & 461 & 4.9 & 56.1 \\
\hline Maternal absence (7-16 years) & 435 & 4.6 & 23.1 \\
\hline Paternal absence (7-16 years) & 1125 & 12.0 & 21.8 \\
\hline In care $(7-16$ years $)$ & 307 & 3.3 & 38.9 \\
\hline Divorce of parents by age 16 years & 882 & 9.4 & 11.2 \\
\hline Parental physical abuse ${ }^{b}$ & 563 & 6.0 & 0.7 \\
\hline Parental sexual abuse ${ }^{\mathrm{b}}$ & 149 & 1.6 & 0.7 \\
\hline Life events at 42 years & & & 2.5 \\
\hline 0 & 4480 & 47.8 & \\
\hline 1 or more & 4601 & 49.1 & \\
\hline $\begin{array}{l}\text { No of cohabiting partnership } \\
\text { separations }\end{array}$ & & & 2.6 \\
\hline 0 or 1 & 8936 & 95.3 & \\
\hline 2 or more & 441 & 4.7 & \\
\hline No of periods of unemployment & & & 0.0 \\
\hline 0 & 5911 & 63.0 & \\
\hline 1 & 1981 & 21.1 & \\
\hline 2 & 672 & 7.2 & \\
\hline 3 & 575 & 6.1 & \\
\hline $\begin{array}{l}\text { CAGE - problems in past year at } 33 \\
\text { years (score of } 2 \text { or more in either } \\
\text { year) }\end{array}$ & 570 & 6.0 & 11.3 \\
\hline $\begin{array}{l}\text { CAGE - problems in past year at } 42 \\
\text { years (score of } 2 \text { or more in either } \\
\text { year) }\end{array}$ & 720 & 7.6 & 4.5 \\
\hline Emotional support at 42 years (no) & 298 & 3.2 & 3.1 \\
\hline Any long-standing illness at 42 years & 2653 & 28.3 & 3.1 \\
\hline Gender (female) & 4715 & 50.3 & 0.0 \\
\hline Social class at 42 years & & & 16.7 \\
\hline I and II & 3453 & 36.8 & \\
\hline IIInm & 1657 & 17.7 & \\
\hline IIIm & 1539 & 16.4 & \\
\hline IV and V & 1161 & 12.4 & \\
\hline Qualifications at 33 years & & & 12.9 \\
\hline None & 632 & 6.7 & \\
\hline O levels & 3654 & 39.0 & \\
\hline A levels or higher & 3872 & 41.3 & \\
\hline Externalizing at 16 years & 803 & 8.5 & 22.9 \\
\hline Internalizing at 16 years & 1092 & 11.6 & 16.6 \\
\hline $\begin{array}{l}\text { Externalizing or internalizing at } 16 \\
\text { years }\end{array}$ & 1594 & 17.0 & 22.4 \\
\hline
\end{tabular}

CAGE, Cutting down, Annoyance by criticism, Guilty feeling, and Eye-openers; nm, non-manual; m, manual.

${ }^{a}$ The percentages are given out of 9377 for each variable: this will underestimate the prevalence for variables with large amounts of missing data, as missing data are included in the total percentage out of 9377 .

${ }^{\mathrm{b}}$ Retrospectively reported at 45 years. 
worth living in the past week and $7.2 \%$ scored 2 or more on the depressive ideas scale.

\section{Childhood adversities association with suicidal ideation}

Table 2 shows the odds ratios (ORs) for suicidal ideation at 45 years, for each childhood adversity adjusted for gender, qualifications at 33 years and social class at 42 years. All the childhood adversities, except maternal absence, were significantly associated with increased odds of depressive ideas. Physical abuse by a parent and sexual abuse by a parent were associated with a 3-fold increased odds of reporting depressive ideas. All of the childhood adversities were significantly associated with increased odds of feeling life is not worth living in the past week, except maternal absence and neglected appearance. There was an interaction by gender for the effect of divorce of parents on having felt life not worth living in the past week, with an association for males [adjusted OR (AOR) 2.94, 95\% confidence interval (CI) 1.68-5.13] but not females. The odds of suicidal ideation increased with the number of childhood adversities reported.

\section{Childhood adversities and recent life events at 45 years}

Table 2 shows the AORs of reporting any recent life event at 45 years for each childhood adversity measure. Associations were observed between illness in the household, being in care, divorce by age 16 years, physical abuse and sexual abuse on recent life events at 45 years. The cumulative number of childhood adversities reported was only associated with recent life events for females, with two adversities or three or more adversities significantly increasing the odds for recent life events (AOR 1.31, 95\% CI 1.03-1.66; AOR 1.80 95\% CI 1.42-2.28, respectively).

\section{Childhood adversities and psychological distress at 16 years}

After adjustment for gender and social class at birth, all the childhood adversities were associated with externalizing and internalizing problems at 16 years (Table 2). As associations were similar for the two measures at 16 years, further analyses combined 'any externalizing or internalizing problems at 16 years' (yes/no). All childhood adversities were associated with psychological distress at 16 years, the strength of the association increasing as the number of adversities increased.

\section{Adulthood stressors and midlife suicidal ideation}

Table 3 shows that all the adulthood stressors were significantly associated with suicidal ideation at
45 years; cohabiting partnership separations, periods of unemployment, problem drinking and long-standing illness increased the odds of depressive ideas around 1.5- to 2-fold. Low emotional support only increased the odds of depressive ideas for females.

\section{Internalizing and externalizing disorders as mediating factors}

Table 4 shows that after adjustment for any internalizing or externalizing disorder at 16 years and the adulthood stressors, illness in the household, paternal absence, divorce by 16 years, physical abuse, sexual abuse and the cumulative number of adversities remained significantly associated with suicidal ideation. Psychological distress at 16 years mediated these associations by 1.80 to $5.57 \%$. Adulthood problem drinking mediated these associations by 1.75 to $9.22 \%$. Table 4 also shows that after adjustment for the adulthood stressors and psychological distress at 16 years, physical abuse, sexual abuse and the cumulative number of adversities remained significantly associated with depressive ideas at 45 years. Psychological distress at 16 years mediated these associations by $3.41 \%$ for physical abuse and $4.99 \%$ for sexual abuse. Problem drinking mediated these associations by $2.80 \%$ for physical abuse and $6.37 \%$ for sexual abuse.

\section{Adult life events and interpersonal difficulties as mediating factors}

Table 5 shows the indirect percentage of the total mediation effect of the associations by life events: the associations of childhood adversities with depressive ideas were mediated by $5.59 \%$ for illness in the household, $11.79 \%$ for physical abuse, and $8.16 \%$ for sexual abuse. Cohabiting partnership separations mediated these associations by $2.97 \%$ for physical abuse and $2.73 \%$ for sexual abuse: the association between illness in the household and depressive ideas was suppressed by cohabiting partnership separations, but only marginally $(-0.88 \%)$. The total percentage of mediation of the associations with feeling that life is not worth living by life events ranged from $1.55 \%$ for illness in the household to $9.59 \%$ for physical abuse. The indirect percentage of the mediation effect of these associations by cohabiting partnership separations ranged from 1.27 for paternal absence to $5.22 \%$ for physical abuse. Again, the association between illness in the household and suicidal ideation was marginally suppressed by cohabiting partnership separations $(-0.50 \%)$.

We created a combined score describing overall adversity in adulthood. The sum of the dichotomous adversity measures included: number of partnerships, number of periods unemployed, drinking problems at 33 or 42 years, lack of emotional support at 42 years and 
Table 2. Increase in risk for (a) suicidal ideation and depressive ideas at 45 years, (b) recent life events and (c) psychological ill health at 16 years, for the presence of each individual adversity/maltreatment ${ }^{\text {a }}$

\begin{tabular}{|c|c|c|c|c|c|c|}
\hline \multirow[b]{2}{*}{ Adversity } & \multicolumn{2}{|l|}{ Suicidal ideation } & \multirow{2}{*}{$\begin{array}{l}\text { Recent life events } \\
\text { Life events at } \\
45 \text { years, } 1 v .0\end{array}$} & \multicolumn{3}{|c|}{ Psychological ill health at 16 years } \\
\hline & $\begin{array}{l}\text { In the past week have you felt } \\
\text { that life isn't worth living? }\end{array}$ & Depressive ideas & & $\begin{array}{l}\text { Internalizing or } \\
\text { externalizing at } 16 \text { years }\end{array}$ & $\begin{array}{l}\text { Internalizing at } \\
16 \text { years }\end{array}$ & $\begin{array}{l}\text { Externalizing at } \\
16 \text { years }\end{array}$ \\
\hline Illness in the household & $2.23(1.59-3.14)^{* * *}$ & $1.38(1.11-1.70)^{* *}$ & $1.12(1.00-1.26)^{*}$ & $1.53(1.33-1.75)^{* * *}$ & $1.46(1.26-1.69)^{* * *}$ & $1.58(1.30-1.91)^{* * *}$ \\
\hline $\begin{array}{l}\text { Neglected/underfed appearance at 7-11 } \\
\text { years }\end{array}$ & $1.61(0.88-2.95)$ & $1.47(1.00-2.14)^{*}$ & $1.05(0.83-1.33)$ & $2.76(2.22-3.42)^{* * *}$ & $2.36(1.85-3.00)^{* * *}$ & $2.73(2.03-3.67)^{* * *}$ \\
\hline Maternal absence & $0.97(0.51-1.83)$ & $1.02(0.72-1.43)$ & $1.02(0.85-1.23)$ & $1.61(1.29-2.01)^{* * *}$ & $1.58(1.19-2.08)^{* *}$ & $1.68(1.27-2.22)^{* * *}$ \\
\hline Paternal absence & $2.12(1.49-3.00)^{* * *}$ & $1.34(1.08-1.66)^{* *}$ & $1.11(0.98-1.26)$ & $1.66(1.43-1.93)^{* * *}$ & $1.50(1.26-1.79)^{* * *}$ & $1.91(1.59-2.30)^{* * *}$ \\
\hline In care & $2.17(1.26-3.74)^{* *}$ & $1.60(1.11-2.31)^{*}$ & $1.42(1.14-1.77)^{* *}$ & $2.54(2.03-3.17)^{* * *}$ & $2.22(1.73-2.86)^{* * *}$ & $2.87(2.20-3.76)^{* * *}$ \\
\hline Divorce of parents by age 16 years ${ }^{\mathrm{b}}$ & $1.82(1.24-2.66)^{* *}+$ & $1.32(1.04-1.68)^{*}$ & $1.19(1.03-1.38)^{*}$ & $1.75(1.48-2.08)^{* * *}$ & $1.53(1.26-1.87)^{* * *}$ & $2.09(1.69-2.57)^{* * *}$ \\
\hline Males & $2.94(1.68-5.13)^{* * *}$ & & & & & \\
\hline Females & $1.29(0.75-2.22)$ & & & & & \\
\hline Parental physical abuse $^{c}$ & $3.07(2.07-4.56)^{* * *}$ & $2.83(2.23-3.59)^{* * *}$ & $1.78(1.49-2.14)^{* * *}$ & $1.77(1.44-2.19)^{* * *}$ & $1.30(1.01-1.68)^{*}$ & $2.42(1.91-3.07)^{* * *}$ \\
\hline Parental sexual abuse ${ }^{c}$ & $3.55(1.95-6.46)^{* * *}$ & $3.06(2.05-4.54)^{* * *}$ & $1.64(1.16-2.32)^{* *}$ & $2.75(1.88-4.02)^{* * *}$ & $2.10(1.38-3.20)^{* * *}$ & $3.77(2.50-5.69)^{* * *}$ \\
\hline \multicolumn{7}{|l|}{ Cumulative adversity scale at $7-16$ years $^{\mathrm{d}}$} \\
\hline 1 & $1.84(1.13-2.98)^{*}$ & $1.43(1.10-1.85)^{* *}$ & $1.15(1.02-1.30)^{*}$ & $1.50(1.28-1.74)^{* * *}$ & $1.38(1.16-1.63)^{* * *}$ & $1.64(1.30-2.07)^{* * *}$ \\
\hline Males & & & $1.14(0.95-1.38)$ & & & \\
\hline Females & & & $1.16(0.99-1.35)$ & & & \\
\hline 2 & $2.56(1.53-4.29)^{* * *}$ & $1.56(1.17-2.08)^{* *}$ & $1.24(1.05-1.46)^{*}$ & $1.95(1.57-2.42)^{* * *}$ & $1.63(1.28-2.09)^{* * *}$ & $2.34(1.76-3.12)^{* * *}$ \\
\hline Males & & & $1.17(0.92-1.47)$ & & & \\
\hline Females & & & $1.31(1.03-1.66)^{*}$ & & & \\
\hline 3 or more & $4.31(2.67-6.94)^{* * *}$ & $2.24(1.71-2.93)^{* * *}$ & $1.39(1.17-1.66)^{* * *++}$ & $3.25(2.64-4.00)^{* * *}$ & $2.60(2.06-3.28)^{* * *}$ & $4.09(3.21-5.23)^{* * *}$ \\
\hline Males & & & $1.07(0.83-1.39)$ & & & \\
\hline Females & & & $1.80(1.42-2.28)^{* * *}$ & & & \\
\hline
\end{tabular}

Data are given as adjusted odds ratio (95\% confidence interval).

a Suicidal ideation and recent life events models adjusted for social class at 42 years, qualifications at 33 years, and gender. Psychological ill health at 16 years model adjusted for gender and social class at 7 years.

${ }^{\mathrm{b}}$ Reported at 33 years.

${ }^{\mathrm{c}}$ Reported at 45 years.

${ }^{\mathrm{d}}$ Measure of adversity only counts absent mother and absent father if being in care and divorce are not present; also does not include illness as this is too frequent. All measures are prospective (measured in childhood) except divorce of parents by age 16 years, parental physical abuse and parental sexual abuse. In all analyses the reference group is no exposure to the adversity or 0 for the cumulative adversity measure.

${ }^{*} p \leqslant 0.05,{ }^{* *} p \leqslant 0.01,{ }^{* * *} p \leqslant 0.001$.

No significant gender interactions were observed with the following exceptions: $+p=0.032$; $++p=0.004$. 
Table 3. Increase in odds for suicidal ideation and depressive ideas at 45 years, for no. of partnerships, no. of periods unemployed, drinking problems at 33 or 42 years, lack of emotional support at 42 years, long-standing illness at 42 years, internalizing problems and externalizing problems at 16 years $^{\mathrm{a}}$

Suicidal ideation

Adversity: adult stressor indicator

In the past week have you

felt that life isn't worth living? Depressive ideas

\begin{tabular}{|c|c|c|c|}
\hline No. of cohabiting partnership separations, $16-42$ years & $2+$ & $1.96(1.18-3.24)^{* *}$ & $1.74(1.29-2.37)^{* * *}$ \\
\hline \multirow[t]{9}{*}{ No. of periods of unemployment, $16-42$ years } & 1 & $1.91(1.37-2.68)^{* * *}$ & $1.39(1.14-1.68)^{* * *}$ \\
\hline & Males & $1.58(0.86-2.90)$ & \\
\hline & Females & $2.14(1.43-3.20)^{* * *}$ & \\
\hline & 2 & $1.45(0.83-2.54)$ & $1.51(1.13-2.01)^{* *}$ \\
\hline & Males & $1.73(0.78-3.87)$ & \\
\hline & Females & $1.28(0.58-2.84)$ & \\
\hline & $3+$ & $1.95(1.15-3.32)^{*} t^{b}$ & $1.79(1.32-2.42)^{* * *}$ \\
\hline & Males & $2.96(1.55-5.63)^{* * *}$ & \\
\hline & Females & $0.55(0.13-2.27)$ & \\
\hline $\begin{array}{l}\text { CAGE - problems in past year either at } 33 \text { or } 42 \text { years } \\
\text { (score of } 2 \text { or more in either year) }\end{array}$ & $2+$ & $2.68(1.87-3.83)^{* * *}$ & $2.25(1.83-2.77)^{* * *}$ \\
\hline \multirow[t]{3}{*}{ Emotional support at 42 years } & No & $1.48(0.76-2.89)$ & $1.89(1.31-2.73)^{* * *}+^{c}$ \\
\hline & Males & & $1.39(0.81-2.38)$ \\
\hline & Females & & $2.90(1.70-4.93)^{* * *}$ \\
\hline Any long-standing illness at 42 years & Yes & $2.44(1.80-3.30)^{* * *}$ & $2.07(1.76-2.44)^{* * *}$ \\
\hline \multicolumn{4}{|l|}{ Childhood psychological distress } \\
\hline Internalizing or externalizing at 16 years & Yes & $1.59(1.08-2.34)^{*}$ & $1.59(1.30-1.95)^{* * *}$ \\
\hline Internalizing at 16 years & Yes & $1.54(0.99-2.39)$ & $1.61(1.29-2.02)^{* * *}$ \\
\hline \multirow[t]{3}{*}{ Externalizing at 16 years } & Yes & $1.63(1.09-2.43)^{*}$ & $1.58(1.23-2.04)^{* * *} \mathrm{t}^{\mathrm{d}}$ \\
\hline & Males & & $1.15(0.76-1.75)$ \\
\hline & Females & & $1.98(1.45-2.71)^{* * *}$ \\
\hline
\end{tabular}

Data are given as adjusted odds ratio (95\% confidence interval).

CAGE, Cutting down, Annoyance by criticism, Guilty feeling, and Eye-openers.

${ }^{a}$ Adult stressors model adjusted for gender, social class at 42 years, and qualifications at 33 years. Psychological ill health at 16 years model adjusted for gender and social class at 7 years.

${ }^{*} p \leqslant 0.05,{ }^{* *} p \leqslant 0.01,{ }^{* * *} p \leqslant 0.001$.

$\mathrm{t}^{\mathrm{b}}$ Gender interaction $p=0.042, \mathrm{t}^{\mathrm{c}}$ gender interaction $p=0.034, \mathrm{t}^{\mathrm{d}}$ gender interaction $p=0.018$.

long-standing illness at 42 years. We adjusted analyses for gender, social class at 42 years and qualifications at 33 years (AOR for life not worth living: cumulative adversity, one adversity AOR 1.75, 95\% CI 1.08-2.84; two adversities AOR 2.39, 95\% CI 1.42-4.02; three or more adversities AOR 3.79, 95\% CI 2.33-6.15; AOR for depressive thoughts: one adversity AOR 1.36, 95\% CI 1.05-1.76; two adversities AOR 1.44, 95\% CI 1.08-1.92; three or more adversities AOR 1.94, 95\% CI 1.47-2.56).

We carried out analyses to examine how much this adult adversity score might mediate the association between childhood adversity and suicidal ideation. The indirect percentage of the total mediation effect was between 3.28 and 8.63 for feeling that life was not worth living and between 7.86 and 8.67 for depressive ideas. The percentage of mediation explained was of little greater magnitude than the individual life events and interpersonal difficulties (see Supplementary Table).

\section{Discussion}

The aims of our study were to assess whether the effects of childhood adversity on suicidal ideation extended beyond adolescence to midlife and whether this was partially mediated by adolescent internalizing disorders, externalizing disorders and adult exposure to life events and interpersonal difficulties. We confirmed that specific childhood adversities which included illness in the household, paternal absence and divorce prospectively predict suicidal ideation at 45 years even after adjustment for confounding and mediating factors. Retrospectively recalled parental sexual and physical abuse also show strong associations with suicidal ideation at 45 years. Childhood adversity predicts adult life events, supporting continuity of exposure to adversity across the lifecourse. Adulthood interpersonal difficulties predicted suicidal ideation. 
Table 4. Adjusted odds ratios (AORs) and 95\% confidence intervals (CIs) with supporting mediation effect showing the increase in odds for suicidal ideation and depressive ideas at 45 years, for each increase in the number of reports of the adversities ${ }^{\mathrm{a}}$

\begin{tabular}{|c|c|c|c|c|c|c|}
\hline \multirow[b]{3}{*}{ Adversity } & \multicolumn{3}{|c|}{ In the past week have you felt that life isn't worth living? } & \multicolumn{3}{|l|}{ Depressive ideas } \\
\hline & \multirow[b]{2}{*}{ AOR $(95 \% \mathrm{CI})$} & \multicolumn{2}{|c|}{ Indirect percentage of total mediation effect } & \multirow{2}{*}{ AOR $(95 \% \mathrm{CI})$} & \multicolumn{2}{|c|}{ Indirect percentage of total mediation effect } \\
\hline & & $\begin{array}{l}\text { Psychological ill health } \\
\text { at } 16 \text { years } \\
\text { Mean \% }(95 \% \mathrm{CI})\end{array}$ & $\begin{array}{l}\text { Any drinking problems } \\
\text { at } 33 \text { or } 42 \text { years } \\
\text { Mean } \%(95 \% \mathrm{CI})\end{array}$ & & $\begin{array}{l}\text { Psychological ill } \\
\text { health at } 16 \text { years } \\
\text { Mean \% (95\% CI) }\end{array}$ & $\begin{array}{l}\text { Any drinking problems } \\
\text { at } 33 \text { or } 42 \text { years } \\
\text { Mean } \%(95 \% \mathrm{CI})\end{array}$ \\
\hline Illness in the household & $2.00(1.41-2.83)^{* * *}$ & $1.80(1.19-3.22)$ & $1.75(1.09-3.18)$ & $1.24(1.00-1.55)$ & & \\
\hline Neglected/underfed appearance, 7-11 years & $1.36(0.73-2.54)$ & & & $1.25(0.83-1.88)$ & & \\
\hline Maternal absence & $0.85(0.45-1.63)$ & & & $0.90(0.63-1.28)$ & & \\
\hline Paternal absence & $1.92(1.34-2.75)^{* * *}$ & $2.93(1.77-6.23)$ & $2.64(1.58-5.47)$ & $1.19(0.95-1.49)$ & & \\
\hline In care & $1.74(0.98-3.11)$ & & & $1.28(0.87-1.89)$ & & \\
\hline Divorce of parents by age 16 years ${ }^{b}$ & $1.58(1.07-2.35)^{*}$ & $5.20(-1.34$ to 29.15$)$ & $7.18(-1.86$ to 38.99$)$ & $1.14(0.89-1.46)$ & & \\
\hline Parental physical abuse ${ }^{\mathrm{c}}$ & $2.25(1.49-3.41)^{* * *}$ & $3.79(1.93-11.07)$ & $4.19(2.12-12.48)$ & $2.13(1.66-2.74)^{* * *}$ & $3.41(2.29-5.75)$ & $2.80(1.88-4.75)$ \\
\hline Parental sexual abuse $^{c}$ & $2.64(1.42-4.93)^{* *}$ & $5.57(1.26-32.12)$ & $9.22(2.57-51.23)$ & $2.32(1.53-3.53)^{* * *}$ & $4.99(2.90-11.16)$ & $6.37(3.70-14.22)$ \\
\hline \multicolumn{7}{|l|}{ Cumulative adversity scale } \\
\hline 1 & $1.67(1.03-2.70)^{*}$ & & & $1.30(1.00-1.69)^{*}$ & & \\
\hline 2 & $2.21(1.31-3.74)^{* *}$ & & & $1.34(1.00-1.80)$ & & \\
\hline 3 or more & $3.25(1.97-5.37)^{* * *}$ & & & $1.68(1.27-2.24)^{* * *}$ & & \\
\hline
\end{tabular}

a Adjusted for gender, social class at 42 years, qualifications at 33 years, life events at 45 years, number of partnerships in adulthood, number of periods of unemployment in adulthood, emotional support at 42 years, problem drinking at either 33 or 42 years, and long-standing illness at 42 years and psychological distress at 16 years (any internalizing or externalizing at 16 years).

${ }^{\mathrm{b}}$ Reported at 33 years.

${ }^{\mathrm{c}}$ Reported at 45 years.

${ }^{*} p \leqslant 0.05,{ }^{* *} p \leqslant 0.01,{ }^{* * *} p \leqslant 0.001$. 
Table 5. Adjusted odds ratios (AORs) and 95\% confidence intervals (CIs) with supporting mediation effect showing the increase in odds for suicidal ideation and depressive ideas at 45 years, for each childhood adversity ${ }^{\mathrm{a}}$

\begin{tabular}{|c|c|c|c|c|c|c|}
\hline \multirow[b]{3}{*}{ Adversity } & \multicolumn{3}{|c|}{ In the past week have you felt that life isn't worth living? } & \multicolumn{3}{|l|}{ Depressive ideas } \\
\hline & \multirow[b]{2}{*}{ AOR $(95 \% \mathrm{CI})$} & \multicolumn{2}{|c|}{ Indirect percentage of total mediation effect } & \multirow[b]{2}{*}{ AOR $(95 \% \mathrm{CI})$} & \multicolumn{2}{|c|}{ Indirect percentage of total mediation effect } \\
\hline & & $\begin{array}{l}\text { Life events } \\
\text { Mean \% (95\% CI) }\end{array}$ & $\begin{array}{l}\text { Number of partnerships } \\
\text { in adulthood } \\
\text { Mean \% (95\% CI) }\end{array}$ & & $\begin{array}{l}\text { Life events } \\
\text { Mean \% (95\% CI) }\end{array}$ & $\begin{array}{l}\text { Number of partnerships } \\
\text { in adulthood } \\
\text { Mean } \%(95 \% \mathrm{CI})\end{array}$ \\
\hline Illness in the household & $2.00(1.41-2.83)^{* * *}$ & $1.55(1.01-2.78)$ & $-0.50(-1.11$ to -0.17$)$ & $1.24(1.00-1.55)$ & $5.59(-1.15$ to 24.44$)$ & -0.88 (-6.14 to 2.95$)$ \\
\hline Neglected/underfed appearance at $7-11$ years & $1.36(0.73-2.54)$ & & & $1.25(0.83-1.88)$ & & \\
\hline Maternal absence & $0.85(0.45-1.63)$ & & & $0.90(0.63-1.28)$ & & \\
\hline Paternal absence & $1.92(1.34-2.75)^{* * *}$ & $2.49(1.45-5.62)$ & $1.27(0.76-2.91)$ & $1.19(0.95-1.49)$ & & \\
\hline In care & $1.74(0.98-3.11)$ & & & $1.28(0.87-1.89)$ & & \\
\hline Divorce of parents by age 16 years ${ }^{\mathrm{b}}$ & $1.58(1.07-2.35)^{*}$ & $6.34(-7.16$ to 36.75$)$ & $2.27(-3.72$ to 14.19$)$ & $1.14(0.89-1.46)$ & & \\
\hline Parental physical abuse ${ }^{c}$ & $2.25(1.49-3.41)^{* * *}$ & $9.59(4.97-27.88)$ & $5.22(2.65-16.38)$ & $2.13(1.66-2.74)^{* * *}$ & 11.79 (8.14-19.09) & $2.97(2.01-5.02)$ \\
\hline Parental sexual abuse $^{c}$ & $2.64(1.42-4.93)^{* *}$ & $6.59(2.40-38.36)$ & $4.71(0.93-28.69)$ & $2.32(1.53-3.53)^{* * *}$ & $8.16(4.72-18.53)$ & $2.73(1.57-6.50)$ \\
\hline \multicolumn{7}{|l|}{ Cumulative adversity scale } \\
\hline 1 & $1.67(1.03-2.70)^{*}$ & & & $1.30(1.00-1.69)^{*}$ & & \\
\hline 2 & $2.21(1.31-3.74)^{* *}$ & & & $1.34(1.00-1.80)$ & & \\
\hline 3 or more & $3.25(1.97-5.37)^{* * *}$ & & & $1.68(1.27-2.24)^{* * *}$ & & \\
\hline
\end{tabular}

a Adjusted for gender, social class at 42 years, qualifications at 33 years, life events at 45 years, number of partnerships in adulthood, number of periods of unemployment in adulthood, emotional support at 42 years, problem drinking at 33 or 42 years, long-standing illness at 42 years and psychological distress at 16 years (any internalizing or externalizing at 16 years).

\footnotetext{
${ }^{b}$ Reported at 33 years.

${ }^{\mathrm{c}}$ Reported at 45 years.

${ }^{*} p \leqslant 0.05,{ }^{* *} p \leqslant 0.01,{ }^{* * *} p \leqslant 0.001$
} 
In terms of investigation of mediation, psychological ill-health in childhood partially mediated the association of illness in the household, paternal absence and physical and sexual abuse. Adult life events partially mediated the association of paternal absence, divorce and physical and sexual abuse, while partnerships in adulthood and problem drinking partially mediated the association of sexual and physical abuse. We have confirmed our hypotheses that some childhood adversities are associated with midlife suicidal ideation and that this is partly mediated by subsequent life events, internalizing and externalizing disorders, although the variance explained in mediation is small. Our findings support Kendler's aetiological framework for affective disorders (Kendler et al. 2002, 2006).

Studies of youth suicide have demonstrated the importance of parent-related events in the family such as parental hospital admission with mental illness, parental divorce and marital disruption (Fergusson et al. 2000) as risk factors. We found that these risks persist into adulthood in our study, as in other studies (Agerbo et al. 2002). The predictive power of parental illness in the household may partially represent genetic transmission of mental illness susceptibility from parent to child as well as the environmental influence of having a sick parent on the child. Early onset of psychopathology, possibly brought forward by adversity, may develop into clinical psychiatric disorder (Clark et al. 2007) that persists into adult life perpetuating suicidal risk (Fergusson et al. 2000; Dube et al. 2001; Fanous et al. 2004). Adolescent internalizing disorder and adult suicidal ideation have also been linked in another British cohort study (Colman et al. 2007) and adolescent depression and adult psychopathology have been found to be mediating factors for childhood adversity and adult suicidal ideation in the follow-up of the Isle of Wight Study (Pickles et al. 2010). Anxiousness and disruptiveness are also mediating factors for childhood adversity and suicidal attempts in young adults (Wanner et al. 2012). Altogether, lifecourse persistent psychopathology beginning in adolescence seems a key pathway for midlife suicidal ideation.

In terms of other types of childhood adversity sexual (Fergusson et al. 2000; Fanous et al. 2004; Ystgaard et al. 2004; Afifi et al. 2008) and physical abuse (Ystgaard et al. 2004; Enns et al. 2006; Bruwer et al. 2014; Harford et al. 2014) have been associated with suicidal ideation, attempts and completed suicide (Séguin et al. 2007). Life events in childhood (Fergusson et al. 2000) and adulthood, including divorce in adulthood (Dennis et al. 2007), are associated with increased risk of suicidal ideation. Interpersonal difficulties in adolescence predict suicidal attempts in young adulthood
(Johnson et al. 2002). Exposure to childhood adversity is related to increased exposure to midlife events. And, as in our study, there is evidence that selfreported alcohol dependence, an example of externalizing behaviour, partially mediates the effect of sexual and physical abuse (Dube et al. 2001).

Lack of maternal and paternal care has been linked to adult suicidal ideation (Enns et al. 2006; Heider et al. 2007), although we found only an unexpected association with paternal absence, as other studies have found associations with maternal absence, although maternal absence was rare in our population. In this instance the CIs around the estimate will be wide because of the rarity of maternal absence rather than the nature of the effect itself. Despite adjustment for social class and educational attainment some of the effects of paternal absence and divorce on midlife suicidal ideation might relate to financial disadvantage as a consequence of these events in childhood. Bifulco et al. (2002) state that all types of childhood adversity increase the risk of adult affective disorder and suicidal ideation noting dose-response relationships and the importance of psychological abuse. In this context the number of adversities experienced may be important for future risk of suicidal ideation (Enns et al. 2006), although sexual and physical abuse, as severe adversities, carry greater risk.

The magnitude of the effects of the mediating factors of internalizing, externalizing and interpersonal disorders may have been small due to methodological limitations: risk factor exposure misclassification, lack of key variables at different stages of the lifecourse and lack of coverage of all relevant risk factors within the three groups of mediators. Additionally we needed to dichotomize the mediating variables, rather than use continuous scores because of the skewed nature of their distribution. Thus we may have underestimated the effect of the mediators. Moreover, as the models are fully adjusted we only expected to see small levels of mediation as the other covariates in the model also contribute to the outcome. Looking at individual possible mediators on top of the effects of other covariates means that individual mediators are unlikely to explain a large percentage of the associations. However, in our study we may also be missing some key variables that are shaped by childhood adversity and transmit the risk of suicidal ideation across the lifecourse. One of these may be how the experience of adversity influences feelings of self-worth, mastery and the ability to develop positive and trusting relationships. In turn this may influence coping capacities and the ability to ask for help in a crisis (Gunnell et al. 2004). Mastery has been linked to lower levels of suicidal ideation (Fairweather et al. 2007). Childhood adversity and abuse have been linked to coping 
methods for stressors in adulthood linked to disengagement (problem avoidance, social withdrawal and self-criticism), although, surprisingly in this study, not to less social support (Leitenberg et al. 2004). This pattern of behavior may result from stress sensitization following childhood adversity which may hinder emotional processing of adult adverse events. Moreover, difficulties in dealing with adult adversity may accumulate in terms of perceived burden and severe interpersonal difficulties perpetuating and increasing suicidal ideas (Heikkinen et al. 1993).

A common theme across studies of risk factors for suicidal ideation and suicide is low social support and social isolation (Heikkinen et al. 1993; Johnson et al. 2002; Gunnell et al. 2004; Dennis et al. 2007). Our measures of social support were limited across the lifecourse and did not fully capture this dimension. Interpersonal skills deficits as one of the features of cluster B personality disorders with emotional dysregulation, disinhibition and 'thwarted belonginess' may be reasons for increased suicidal attempts in this patient group (May et al. 2012). Future lifecourse studies should attempt to capture the ways people cope with stressors, develop interpersonal relationships and ask for help in relation to suicidal ideation.

It is a strength that we had prospective measurements of childhood adversities and mediating factors at different life stages. To our knowledge this is the first study to examine the role of mediators of prospectively measured childhood adversity and its association with midlife suicidal ideation. It is a limitation that childhood sexual and physical abuse were reported retrospectively (Colman et al. 2016). Also our adversities were measured long before standard scales like the Parental Bonding Instrument had been developed and they were not designed to capture current conceptualizations of adversity. The main limitation of longitudinal cohort study analysis is sample attrition and missing data but we anticipate that multiple imputation has addressed this. Also, at present it is only possible computationally to perform relatively simple mediation analyses.

\section{Conclusions}

Suicidal ideation and completed suicide are not equivalent, and less than 1 in 200 of those with suicidal ideation proceed to suicide (Gunnell et al. 2004). However, in the National Comorbidity Study the conditional probability of making a suicidal attempt among those with suicidal ideation was $57.9 \%$ with a suicide plan and $25.2 \%$ without a plan (Kessler et al. 1999) so that suicidal ideation should be considered an indicator of clinically significant risk both of suicidal attempt and major depressive disorder (Kessler et al. 1999).
Some elements of childhood adversity have an impact on midlife suicidal ideation after adjustment for mediating factors. This is in keeping with effects of adversity in critical periods in childhood having longterm consequences for mental health that may reflect effects on the developing brain and neuroendocrine responses to stress.

Understanding the pathways from adversity to suicidal ideation can inform suicide prevention (Gunnell et al. 2004). Interventions focused on parenting may be most effective in preventing childhood affective disorders and hence the transmission to adulthood (Shonkoff \& Fisher, 2013). Additionally, interventions establishing mentors or significant others as alternative points of support and attachment during childhood would be a viable intervention pathway. Our results indicate that there are both childhood and adulthood factors that increase the risk of suicidal ideation and that interventions with internalizing, externalizing disorders and preventing relationship breakdown in adulthood may be relevant in prevention of the longterm consequences of childhood adversity.

\section{Supplementary material}

The supplementary material for this article can be found at http://dx.doi.org/10.1017/S0033291716002336

\section{Acknowledgements}

We thank the data providers: Centre for Longitudinal Studies, Institute of Education and National Birthday Trust Fund, National Children's Bureau, City University Social Statistics Research Unit (original data producers).

The biomedical examination and related statistical analyses were funded by the Medical Research Council (grant no. G0000934), awarded under the Health of the Public initiative. B.R. was supported by Research Fellowship no. 471429 from the National Health and Medical Research Council of Australia. Research at the UCL Institute of Child Health and Great Ormond Street Hospital for Children is supported by the Department of Health's National Institute of Health Research (NIHR) Biomedical Research Centre.

\section{Declaration of Interest}

None.

\section{References}

Afifi TO, Enns MW, Cox BJ, Asmundson GJG, Stein MB, Sareen J (2008). Population attributable fractions of 
psychiatric disorders and suicide ideation and attempts associated with adverse childhood experiences. American Journal of Public Health 98, 946-952.

Agerbo E, Nordentoft M, Mortensen PB (2002). Familial, psychiatric, and socioeconomic risk factors for suicide in young people: nested case-control study. British Medical Journal 325, 74.

Atherton K, Fuller E, Shepherd P, Strachan DP, Power C (2008). Loss and representativeness in a biomedical survey at age 45 years: 1958 British birth cohort. Journal of Epidemiology and Community Health 62, 216-223.

Bifulco A, Moran PM, Baines R, Bunn A, Stanford K (2002). Exploring psychological abuse in childhood: II. Association with other abuse and adult clinical depression. Bulletin of the Menninger Clinic 66, 241-258.

Bradley RG, Binder EB, Epstein MP, Tang Y, Nair HP, Liu W, Gillespie CF, Berg T, Evces M, Newport DJ, Stowe ZN, Heim CM, Nemeroff CB, Schwartz A, Cubells JF, Ressler KJ (2008). Influence of child abuse on adult depression: moderation by the corticotropin-releasing hormone receptor gene. Archives of General Psychiatry 65, 190-200.

Bruwer B, Govender R, Bishop M, Williams DR, Stein DJ, Seedat $S$ (2014). Association between childhood adversities and long-term suicidality among South Africans from the results of the South African Stress and Health study: a cross-sectional study. BMJ Open 4, e004644.

Clark C, Rodgers B, Caldwell T, Power C, Stansfeld S (2007). Childhood and adulthood psychological ill health as predictors of midlife affective and anxiety disorders - The 1958 British Birth Cohort. Archives of General Psychiatry 64, 668-678.

Clark C, Caldwell T, Power C, Stansfeld SA et al. (2010). Does the influence of childhood adversity on psychopathology persist across the lifecourse? A 45-year prospective study. Annals of Epidemiology 20, 385-394.

Colman I, Kingsbury M, Garad Y, Zeng Y, Naicker K, Patten S, Jones PB, Wild TC, Thompson AH (2016). Consistency in adult reporting of adverse childhood experiences Psychological Medicine 46, 543-549.

Colman I, Wadsworth ME, Croudace TJ, Jones PB (2007). Forty-year psychiatric outcomes following assessment for internalizing disorder in adolescence. American Journal of Psychiatry 164, 126-133.

Corcoran P, Gallagher J, Keeley HS, Arensman E, Perry IJ (2006). Adverse childhood experiences and lifetime suicide ideation: a cross-sectional study in a non-psychiatric hospital setting. Irish Medical Journal 99, 42-45.

Dennis M, Baillon S, Brugha T, Lindesay J, Stewart R, Meltzer $H$ (2007). The spectrum of suicidal ideation in Great Britain: comparisons across a 16-74 years age range. Psychological Medicine 37, 795-805.

Dube SR, Anda RF, Felitti VJ, Chapman DP, Williamson DF, Giles WH (2001). Childhood abuse, household dysfunction, and the risk of attempted suicide throughout the lifespan: findings from the Adverse Childhood Experiences Study. Journal of the American Medical Association 286, 3126-3127.

Elander J, Rutter M (1996). Use and development of the Rutter's parents' and teachers' scales. International Journal of Psychiatric Research 6, 63-78.
Enns MW, Cox BJ, Afifi TO, de Graaf R, Ten Have M, Sareen J (2006). Childhood adversities and risk for suicidal ideation and attempts: a longitudinal population-based study. Psychological Medicine 36, 1769-1778.

Fairweather AK, Anstey KJ, Rodgers B, Jorm AF, Christensen $H$ (2007). Age and gender differences among Australian suicide ideators: prevalence and correlates. Journal of Nervous and Mental Disease 195, 130-136.

Fanous AH, Prescott CA, Kendler KS (2004). The prediction of thoughts of death or self-harm in a population-based sample of female twins. Psychological Medicine 34, 301-312.

Fergusson DM, Woodward LJ, Horwood LJ (2000). Risk factors and life processes associated with the onset of suicidal behaviour during adolescence and early adulthood. Psychological Medicine 30, 23-29.

Ghodsian M (1983). Measuring behaviour in the school and home. In Growing Up in Britain (ed. K Fogelman), pp. 329338. The Macmillan Press Ltd: London.

Graham H, Power C (2004). Childhood disadvantage and health inequalities: a framework for policy based on lifecourse research. Child: Care, Health and Development 30, 671-678.

Gunnell D, Harbord R, Singleton N, Jenkins R, Lewis G (2004). Factors influencing the development and amelioration of suicidal thoughts in the general population. Cohort study. British Journal of Psychiatry 185, 385-393.

Hancock M, Elliott J, Johnson J, Bukodi E (2011a). National Child Development Study: Activity Histories 1974-2009. Centre for Longitudinal Studies, Institute of Education: London.

Hancock M, Elliott J, Johnson J, Bukodi E (2011b). National Child Development Study: Partnership Histories 1974-2008. Centre for Longitudinal Studies, Institute of Education: London.

Harford TC, Yia H, Grant BF (2014). Associations between childhood abuse and interpersonal aggression and suicide attempt among U.S. adults in a national study. Child Abuse and Neglect 38, 1389-1398.

Heider D, Bernert S, Matschinger H, Haro JM, Alonso J, Angermeyer MC; ESEMeD/MHEDEA 2000 Investigators (2007). Parental bonding and suicidality in adulthood. Australian and New Zealand Journal of Psychiatry 41, 66-73.

Heikkinen M, Aro H, Lonnqvist J (1993). Life events and social support in suicide. Suicide and Life-threatening Behavior 23, 343-358.

Hicks R \& Tingley D (2011). Causal mediation analysis. Stata Journal 11, 1-15.

Hornung OP, Heim CM (2014). Gene-environment interactions and intermediate phenotypes: early trauma and depression. Frontiers in Endocrinology 5, 14.

Johnson JG, Cohen P, Gould MS, Kasen S, Brown J, Brook JS (2002). Childhood adversities, interpersonal difficulties, and risk for suicide attempts during late adolescence and early adulthood. Archives of General Psychiatry 59, 741-749.

Kendler KS, Eaves LJ (1986). Models for the joint effect of genotype and environment on liability to psychiatric illness. American Journal of Psychiatry 143, 279-289.

Kendler KS, Gardner CO, Prescott CA (2002). Toward a comprehensive developmental model for major depression in women. American Journal of Psychiatry 159, 1133-1145. 
Kendler KS, Gardner CO, Prescott CA (2006). Toward a comprehensive developmental model for major depression in men. American Journal of Psychiatry 163, 115-124.

Kessler RC, Borges G, Walters EE (1999). Prevalence of and risk factors for lifetime suicide attempts in the National Comorbidity Survey. Archives of General Psychiatry 56, 617-626.

Leitenberg H, Gibson LE, Novy PL (2004). Individual differences among undergraduate women in methods of coping with stressful events: the impact of cumulative childhood stressors and abuse. Child Abuse and Neglect 28, 181-192.

Lewis G, Pelosi AJ, Araya R, Dunn G (1992). Measuring psychiatric-disorder in the community - a standardized assessment for use by lay interviewers. Psychological Medicine 22, 465-486.

May AM, Klonsky ED, Klein DN (2012). Predicting future suicide attempts among depressed suicidal ideators: a 10year longitudinal study. Journal of Psychiatric Research 46, 946-952.

Mayfield D, McLeod G, Hall P (1974). The CAGE questionnaire: validation of a new alcoholism screening instrument. American Journal of Psychiatry 131, 1121-1123.

McGowan PO, Sasaki A, D'Alessio AC, Dymov S, Labonté B, Szyf M, Turecki G, Meaney MJ (2009). Epigenetic regulation of the glucocorticoid receptor in human brain associates with childhood abuse. Nature Neuroscience 12, 342-348.

Office of Population Censuses and Surveys (1980). Classification of Occupations. HMSO: London.

Pickles A, Aglan A, Collishaw S, Messer J, Rutter M, Maughan B (2010). Predictors of suicidality across the life span: the Isle of Wight study. Psychological Medicine 40, 1453-1466.

Power C, Elliott J (2006). Cohort profile: 1958 British birth cohort (National Child Development Study). International Journal of Epidemiology 35, 34-41.
Rosenman S \& Rodgers B (2004). Childhood adversity in an Australian population. Social Psychiatry and Psychiatric Epidemiology 39, 695-702.

Rubin DB (1987). Multiple Imputation for Nonresponse in Surveys. J. Wiley \& Sons: New York.

Rutter M (1967). A children's behaviour questionnaire for completion by teachers - preliminary findings. Journal of Child Psychology and Psychiatry and Allied Disciplines 8, 1-11.

Séguin M, Lesage A, Turecki G, Bouchard M, Chawky N, Tremblay N, Daigle F, Guy A (2007). Life trajectories and burden of adversity: mapping the developmental profiles of suicide mortality. Psychological Medicine 37, 1575-1583.

Shonkoff JP, Fisher PA (2013). Rethinking evidence-based practice and two-generation programs to create the future of early childhood policy. Development and Psychopathology 25, 1635-1653.

Stansfeld SA, Clark C, Rodgers B, Caldwell T, Power C (2008). Childhood and adulthood socio-economic position and midlife depressive and anxiety disorders. British Journal of Psychiatry 192, 152-153.

Tiet QQ, Bird HR, Davies M, Hoven C, Cohen P, Jensen PS, Goodman S (1998). Adverse life events and resilience. Journal of the American Academy of Child and Adolescent Psychiatry 37, 1191-1200.

Wanner B, Vitaro F, Tremblay RE, Turecki G (2012). Childhood trajectories of anxiousness and disruptiveness explain the association between early-life adversity and attempted suicide. Psychological Medicine 42, 2373-2382.

Windsor TD, Anstey KJ, Butterworth P, Rodgers B (2008). Behavioral approach and behavioral inhibition as moderators of the association between negative life events and perceived control in midlife. Personality and Individual Differences 44, 1080-1092.

Ystgaard M, Hestetun I, Loeb M, Mehlum L (2004). Is there a specific relationship between childhood sexual and physical abuse and repeated suicidal behavior? Child Abuse and Neglect 28, 863-875. 